\title{
Functional Recovery in Traumatic Spinal Cord Injury after Transplantation of Multineurotrophin-Expressing Glial- Restricted Precursor Cells
}

\author{
Qilin Cao, ${ }^{1,2}$ Xiao-Ming Xu, ${ }^{1,2,3}$ William H. DeVries, ${ }^{1,2}$ Gaby U. Enzmann, ${ }^{1,2}$ Peipei Ping ${ }^{4}$ Pantelis Tsoulfas, ${ }^{5,6}$ \\ Patrick M. Wood, ${ }^{5,6}$ Mary Bartlett Bunge, ${ }^{5,6,7}$ and Scott R. Whittemore ${ }^{1,2,3}$ \\ ${ }^{1}$ Kentucky Spinal Cord Injury Research Center and Departments of ${ }^{2}$ Neurological Surgery, ${ }^{3}$ Anatomical Science and Neurobiology, and ${ }^{4}$ Medicine, \\ University of Louisville, Louisville, Kentucky 40202, and ${ }^{5}$ The Miami Project to Cure Paralysis and Departments of ${ }^{~}$ Neurological Surgery and ${ }^{7}$ Cell Biology \\ and Anatomy, University of Miami, Miami, Florida 33136
}

Demyelination contributes to the physiological and behavioral deficits after contusive spinal cord injury (SCI). Therefore, remyelination may be an important strategy to facilitate repair after SCI. We show here that rat embryonic day 14 spinal cord-derived glial-restricted precursor cells (GRPs), which differentiate into both oligodendrocytes and astrocytes, formed normal-appearing central myelin around axons of cultured DRG neurons and had enhanced proliferation and survival in the presence of neurotrophin 3 (NT3) and brain-derived neurotrophin factor (BDNF). We infected GRPs with retroviruses expressing the multineurotrophin D15A (with both BDNF and NT3 activities) and then transplanted them into the contused adult thoracic spinal cord at $9 \mathrm{~d}$ after injury. Expression of D15A in the injured spinal cord is five times higher in animals receiving D15A-GRP grafts than ones receiving enhanced green fluorescent protein (EGFP)-GRP or DMEM grafts. Six weeks after transplantation, the grafted GRPs differentiated into mature oligodendrocytes expressing both myelin basic protein (MBP) and adenomatus polyposis coli (APC). Ultrastructural analysis showed that the grafted GRPs formed morphologically normal-appearing myelin sheaths around the axons in the ventrolateral funiculus (VLF) of spinal cord. Expression of D15A significantly increased the percentage of $\mathrm{APC}^{+}$oligodendrocytes of grafted GRPs (15-30\%). Most importantly, 8 of 12 rats receiving grafts of D15A-GRPs recovered transcranial magnetic motor-evoked potential responses, indicating that conduction through the demyelinated VLF axons was restored. Such electrophysiological recovery was not observed in rats receiving grafts of EGFP-GRPs, D15A-NIH3T3 cells, or an injection of an adenovirus expressing D15A. Recovery of hindlimb locomotor function was also significantly enhanced only in the D15A-GRP-grafted animals at 4 and 5 weeks after transplantation. Therefore, combined treatment with neurotrophins and GRP grafts can facilitate functional recovery after traumatic SCI and may prove to be a useful therapeutic strategy to repair the injured spinal cord.

Key words: spinal cord injury; remyelination; glial-restricted precursor cells; transplantation; rat; myelin repair

\section{Introduction}

Demyelination contributes to the dysfunction of the traumatically injured spinal cord in both humans and experimental ani-

Received Jan. 11, 2005; revised June 2, 2005; accepted June 13, 2005.

This work was supported by National Institute of Neurological Diseases and Stroke Grant NS38665 (S.R.W.,P.T., M.B.B P.M.W.), National Center for Research Resources Grant RR15576, the Kentucky Spinal Cord and Head Injury Research Trust, Norton Healthcare, the Commonwealth of Kentucky Research Challenge for Excellence Trust Fund, The Christopher Reeve Paralysis Foundation (S.R.W.), the Paralysis Project of America (Q.L.C., S.R.W., P.M.W., P.T.), National Institute of Neurological Diseases and Stroke Grant NS36350, the Daniel Heumann Fund for Spinal Cord Research (X.M.X.), the Buoniconti Fund (M.B.B., P.M.W.), The Miami Project to Cure Paralysis, The FaBene Foundation, the Wilson Foundation, and the Abramson Foundation (P.T.). Wethank Kim Fentress at the Kentucky Spinal Cord Injury Research Center and Anna Gomez and Margaret Bates at the Miami Project to Cure Paralysis for their expert technical help. The statistical expertise of Darlene Burke and the highly skilled assistance of Cathie Caple of the Analytic Microscopy Core of the Department of Anatomical Science and Neurobiology are also gratefully acknowledged. We thank Dr. Mark Tuszynski for his critical comments on this manuscript. The hybridoma for nestin developed by S. Hockfield was obtained from the Developmental Studies Hybridoma Bank developed under the auspices of the National Institute of Child Health and Human Development and maintained by the Department of Biological Sciences of the University of lowa (lowa City, IA).

Correspondence should be addressed to Dr. Scott R. Whittemore, Kentucky Spinal Cord Injury Research Center, Department of Neurological Surgery, Medical Dental Research Building 616, 511 South Floyd Street, University of Louisville School of Medicine, Louisville, KY 40202. E-mail: swhittemore@louisville.edu.

P. Ping's present address: Departments of Physiology and Medicine, University of California, Los Angeles School of Medicine.

D0I:10.1523/JNEUROSCI.1065-05.2005

Copyright $\odot 2005$ Society for Neuroscience $\quad$ 0270-6474/05/256947-11\$15.00/0 mals (Gledhill et al., 1973; Blight, 1983; Waxman, 1989; Bunge et al., 1993; Cao et al., 2005; Guest et al., 2005; Totoiu and Keirstead, 2005). Remyelination of demyelinated but otherwise intact axons could be an important repair strategy for the treatment of spinal cord injury (SCI) (Blight, 2002). The potential for inducing endogenous precursor cells to differentiate into mature myelinating oligodendrocytes may prove feasible in the future (Horner et al., 2000; McTigue et al., 2001); however, at present, transplantation is the most promising approach for restoring lost myelin. Recent studies have focused on the use of transplanted oligodendrocyte precursor cells (OPCs) or neural stem cells (NSCs) after SCI (Brustle et al., 1999; Keirstead et al., 1999; Liu et al., 2000; Cao et al., 2001; Ogawa et al., 2002; Bambakidis and Miller, 2004; Hill et al., 2004; Hofstetter et al., 2005). Transplantation of embryonic stem cell-derived NSCs or OPCs has led to partial functional improvement after SCI, suggesting the feasibility of facilitating functional recovery from SCI by remyelination (McDonald et al., 1999; Keirstead et al., 2005). However, these studies did not determine whether the enhanced functional recovery resulted from remyelination of demyelinated axons by engrafted cells or by trophic support to spare the white matter (WM) that would oth- 
erwise degenerate. Thus, the relationship between remyelination and functional recovery after traumatic SCI remains unresolved.

Both neurotrophin 3 (NT3) and brain-derived neurotrophic factor (BDNF) regulate neuronal development and axonal regeneration (Xu et al., 1995). They are also important mediators of myelination. Mice lacking functional trkC or NT3 are deficient in both mature oligodendrocytes and OPCs (Kumar et al., 1998). NT3 enhances the survival and proliferation of OPCs in vitro (Barres and Raff, 1994; Kumar et al., 1998; Yan and Wood, 2000; Franklin et al., 2001) and in vivo (Barres et al., 1994). Myelination by oligodendrocytes is also enhanced by NT3 in both cultures of neurons and the injured CNS (McTigue et al., 1998; Yan and Wood, 2000; Jean et al., 2003). BDNF is important for myelin formation in peripheral nerve during development, because inactivation of BDNF signaling by deleting trkB receptors causes myelin deficits both in vivo and in vitro (Cosgaya et al., 2002).

In this study, we grafted glial-restricted precursor cells (GRPs) genetically modified to express D15A, a multineurotrophin that binds trkB and trkC and has both BDNF and NT3 activities (Urfer et al., 1994; Strohmaier et al., 1996), into a contusive SCI. The injury severity was adjusted to cause enough loss of myelin and/or axons to result in electrophysiological and hindlimb locomotor deficits but also sufficient sparing of demyelinated axons to enable remyelination (Cao et al., 2005). We postulated that D15A would enhance remyelination by engrafted GRPs and thus increase functional recovery. Transcranial magnetic motorevoked potential (tcMMEP) responses were used to objectively measure the conduction of demyelinated axons after SCI (Cao et al., 2005; Loy et al., 2002). The relationship between increased remyelination and electrophysiological and behavioral functional recoveries was carefully analyzed. We report here that only the combined treatment with D15A administration and GRP transplantation led to remyelination of demyelinated axons, restoration of axonal conduction, and improvement in hindlimb locomotor recovery.

\section{Materials and Methods}

All animal care and surgical interventions were undertaken in strict accordance with the Public Health Service Policy on Humane Care and Use of Laboratory Animals, Guide for the Care and Use of Laboratory Animals (Institute of Laboratory Animal Resources, National Research Council, 1996), and with the approval of the University of Louisville Institutional Animal Care and Use Committee and Institutional Biosafety Committee.

Preparation of GRPs. GRPs were immunopanned from embryonic day 14 Fischer 344 rat spinal cord using an A2B5 antibody and a protocol modified from previous studies (Mayer-Proschel et al., 1997; Mujtaba et al., 1999). Growth medium, which consisted of DMEM/Ham's F12 (Invitrogen, Carlsbad, CA), N2 and $2 \times$ B27 supplements (each at $1 \times$; Invitrogen), fibroblast growth factor 2 (FGF2) $(20 \mathrm{ng} / \mathrm{ml})$, and plateletderived growth factor aa (PDGFaa) $(10 \mathrm{ng} / \mathrm{ml})$, was changed every other day, and growth factors (FGF2 and PDGFaa, 20 and $10 \mathrm{ng} / \mathrm{ml}$, respectively) were added daily. In all cases, an aliquot of cells was analyzed the following day to determine the efficiency of the immunopanning. Only those cell preparations in which $>95 \%$ of the bound cells expressed A2B5 were used in the experiments. After $\sim 5 \mathrm{~d}$, the cells were passaged. For fluorescence-activated cell sorting (FACS) analysis of embryonic rat GRPs, the cells were stained live with self-conjugated antibodies against A2B5-phycoerythrin and NG2-FITC and analyzed on a FACSCalibur (BD Biosciences, Franklin Lakes, NJ).

To differentiate GRPs in vitro, the cells were plated in polyornithine/ fibronectin-coated six-well plates. The following day, the FGF2 was removed, and $30 \mathrm{ng} / \mathrm{ml}$ thyroid hormone [tri-iodothyronine (T3)] was added to the growth medium. Thus, differentiation medium consisted of DMEM/Ham's F12, $1 \times \mathrm{N} 2$ and $2 \times$ B27 supplements, PDGFaa (10 ng/ $\mathrm{ml})$, and $\mathrm{T} 3(30 \mathrm{ng} / \mathrm{ml})$, and medium was changed every other day. After
$8 \mathrm{~d}$, the cells were fixed and immunohistochemically analyzed for their differentiated phenotypes.

Before transplantation, GRPs were labeled by infection with the LZRS retrovirus encoding either enhanced green fluorescence protein (EGFP) or D15A-EGFP (see below). In some experiments, double labeling with both bromodeoxyuridine (BrdU) and EGFP was used. For BrdU labeling, undifferentiated passage 2 GRPs were incubated in $10 \mu \mathrm{M} \mathrm{BrdU}$ overnight. This resulted in $>90 \%$ labeling efficiency, with no loss of cell viability. For retroviral labeling, GRPs were treated with $1 \mu \mathrm{g} / \mathrm{ml}$ polybrene for $1 \mathrm{~h}$, followed by incubation in growth medium containing LZRS-EGFP or LZRS-D15A-EGFP retrovirus for $4 \mathrm{~h}$. Routinely, $\sim 60 \%$ cells were infected. Two hours before transplantation, the labeled cells were detached from the dishes using a cell lifter, collected by centrifugation at $1000 \times g$ for $4 \mathrm{~min}$, and resuspended in $1 \mathrm{ml}$ of culture medium. After cell count and viability assessment with trypan blue in a hemacytometer, the cell suspension was centrifuged a second time and resuspended in a smaller volume to give a density of $5 \times 10^{4}$ viable cells per microliter. NIH3T3 cells were cultured in DMEM/Ham's F12 containing $10 \%$ FBS and subsequently infected with LZRS-D15A-EGFP, as described above.

Construction and characterization of the D15A-LZRS retrovirus. EGFP and D15A (Urfer et al., 1994) cDNAs were cloned into the LZRS retroviral vector (Kinsella and Nolan, 1996). To generate high titer virus, $\Phi N X$ cells (provided by Dr. Gary Nolan, Stanford University, Stanford, CA) were transfected using GenePORTER 2 (Gene Therapy Systems, San Diego, CA), which routinely gave transfection efficiencies of $50-65 \%$. Selection with $2 \mu \mathrm{g} / \mathrm{ml}$ puromycin begins $48 \mathrm{~h}$ later. To harvest viral supernatant, media was changed to the appropriate serum-free media without mitogens overnight and harvested the next day. We routinely obtain titers of $5 \times 10^{5}$ to $5 \times 10^{6} \mathrm{pfu} / \mathrm{ml}$.

In vitro myelination by GRPs. GRPs were cocultured with embryonic day 15 Sprague Dawley dorsal root ganglion (DRG) neurons, prepared as described previously (Plant et al., 2002). Approximately 5000-7000 neurons were plated per culture. For myelination experiments, cocultures were prepared by adding 50,000 GRPs to purified DRG neuron cultures. Two groups of DRG neuron cultures were maintained without GRPs. The DRG neuron cultures and the cocultures were fed every $2-3 \mathrm{~d}$ with Neurobasal medium containing B27 supplement and L-glutamine for 2 weeks, after which they were divided into four groups, with addition of 10 $\mathrm{ng} / \mathrm{ml}$ NT3, BDNF, both NT3 and BDNF, or no addition, respectively, and were cultured for an additional 2 weeks. The total period of coculture was thus 4 weeks. Subsequently, cultures were processed for either myelin basic protein (MBP) immunohistochemistry or ultrastructural analysis.

Construction of D15A adenovirus. The cDNA encoding D15A was cloned into the E1-deleted Ad5C1 and replication-deficient Ad5-D15A adenovirus was isolated as described previously (Gao et al., 1998). The titer was $1.1 \times 10^{11} \mathrm{pfu} / \mathrm{ml}$.

Secretion and bioactivity of D15A-GRPs in vitro. Secretion and bioactivity of secreted neurotrophin in D15A-GRPs were analyzed in vitro on trkC-PC12 cells (Tsoulfas et al., 1993). The trkC-PC12 cells were grown in DMEM containing $10 \%$ horse serum and $5 \%$ fetal bovine serum. They were induced to differentiate by adding NT3 for $3 \mathrm{~d}$ into the growth medium, and a standard curve was developed using increasing concentrations of recombinant human NT3 (250 and $500 \mathrm{pg} / \mathrm{ml}, 1,2,4,6$, and $10 \mathrm{ng} / \mathrm{ml})$. The differentiated trkC-PC12 cells whose processes were three times longer than their cell body were counted, and the percentage of differentiated/total PC12 cells was calculated. To collect conditioned medium from D15A- or EGFP-GRPs, GRPs were infected with D15A or EGFP retroviruses and grown in DMEM for $2 \mathrm{~d}$. Conditioned medium was collected, and $10 \%$ horse serum and $5 \%$ fetal bovine serum were added. The trkC-PC12 cells were differentiated for $3 \mathrm{~d}$. The percentage of differentiated trkC-PC12 cells in each conditioned medium were counted as described above and were used to determine the bioactivity of the respective conditional mediums using the standard curve established as above. The concentration of NT3 in DMEM, D15A-, or EGFP-GRPs were also assayed by commercially available sandwich technique ELISA kit (R \& D Systems, Minneapolis, MN) following the recommended protocol of the manufacturer. 
Table 1. Description of experimental groups

\begin{tabular}{llrr}
\hline & Description & $n$ (total) & $n$ (BBB) \\
\hline Group 1 & Laminectomy only & 4 & NA \\
Group 2 & Contusion plus DMEM injection & 13 & 11 \\
Group 3 & Contusion plus D15A-GRP transplantation & 13 & 13 \\
Group 4 & Contusion plus EGFP-GRP transplantation & 14 & 12 \\
Group 5 & Contusion plus D15A-NIH3T3 transplantation & 12 & 12 \\
Group 6 & Contusion plus Ad5-D15A injection & 4 & 11 \\
Total & & 60 & 11 \\
\hline
\end{tabular}

Five animals died unexpectedly during the course of the experiment; one from group 2, one from group 3, two from group 4, and one from group 5 . Early data from these animals were omitted from the analysis. Four animals from each group, except for group 5, were initially tested for tcMMEP responses and survival/differentiation of grafted GRPs in the contused spinal cord. After we observed a robust survival of grafted GRPs and the return of tcMMEP responses in the D15A-GRP-grafted animals, an additional eight rats were included in each group, except for groups 1 and 6 , for evaluation of BBB score, tcMMEP responses, and histology. NA, Not applicable; $n$ (BBB), number of animals for which BBB scores were obtained; $n$ (tcMMEP), number of animals for which tcMMEP responses were recorded; $n$ (total), total number of animals at the start of study.

Surgical procedures. Surgical procedures were as described previously (Cao et al., 2001, 2002, 2005). Briefly, after anesthetization with Nembutal $(50 \mathrm{mg} / \mathrm{kg}$, i.p.), adult female Fischer 344 rats received a dorsal laminectomy at the ninth thoracic vertebral level (T9) to expose the spinal cord, and then a $150 \mathrm{kdyn}$ contusive SCI using the Infinite Horizons (IH; Lexington, KY) impactor. At $9 \mathrm{~d}$ after injury, rats were randomly assigned to five groups, as shown in Table 1, which received DMEM, D15A-GRPs, EGFP-GRPs, D15A-NIH3T3 cells, or D15A adenovirus, respectively. Animals were reanesthetized as above, and the laminectomy site was re-exposed. Four injections were made at $1 \mathrm{~mm}$ cranial to, caudal to, and left and right of the lesion at a depth of $1.3 \mathrm{~mm}$ and $0.6 \mathrm{~mm}$ laterally from midline. At each site, $2 \mu \mathrm{l}$ of cell suspension or vehicle was injected through a glass micropipette with an outer diameter of 50-70 $\mu$ land the tip sharp-beveled to $30-50^{\circ}$ at a rate of $0.5 \mu \mathrm{l} / \mathrm{min}$, as described previously (Cao et al., 2001, 2002). Thus, a total of 400,000 cells were grafted into each injured spinal cord. For the adenoviral experiment, a total of $10^{9} \mathrm{pfu}$ of Ad5-D15A in $4 \mu \mathrm{l}$ of DMEM was injected into four sites of the injured spinal cord, as described above. The animals were allowed to survive for 5 weeks after transplantation.

ELISA assessment of in vivo neurotrophin expression in the injured spinal cord. A total of 12 animals received $150 \mathrm{kd} \mathrm{IH}$ contusion SCI as described above. Eight days later, they were then randomly divided into three groups, which received $8 \mu \mathrm{l}$ of D15A-GRPs, EGFP-GRPs, or DMEM, respectively, at four sites as described above. One week after transplantation, animals were killed with an overdose of Nembutal, and $8 \mathrm{~mm}$ of spinal cord (4 $\mathrm{mm}$ from the injured epicenter cranially and caudally, respectively) was used for protein isolation. Spinal cords were homogenized with buffer consisting of $137 \mathrm{~mm} \mathrm{NaCl}, 20 \mathrm{~mm}$ Tris-HCl, $1 \% \mathrm{NP} 40$, and $1 \times$ protease inhibitor cocktail set III (Calbiochem, La Jolla, CA). Protein concentrations were calculated with the BCA protein assay (Pierce, Rockford, IL). Expression of NT3 was examined by commercially available sandwich technique ELISA kit (R \& D Systems) following the recommended protocol of the manufacturer. Oxidized horseradish peroxidase enzymatic products in the microplate wells were read at 450 nm absorbance using a SpectraMax Plus384 plate reader (Molecular Devices, Sunnyvale, CA). Human recombinant NT3 (R \& D Systems) was used to generate a standard curve. NT3 levels were then normalized against total protein. Differences of NT3 expression among three groups was compared with repeated-measures ANOVA followed by StudentNewman-Keuls post hoc test. The level of statistical significance was set at $p<0.05$.

Behavioral assessment. Open-field locomotor testing using the BassoBeattie-Bresnahan (BBB) locomotor rating scale (Basso et al., 1995) was performed at day 7 after injury and once weekly thereafter for 5 weeks after grafting. All of the animals were coded, and behavioral assessments were performed by two investigators blinded with respect to the treatment groups. The mean BBB scores were tallied by injured groups and plotted as a function of time after injury. Changes in BBB scores over time for the four groups were analyzed using repeated-measures ANOVA with the between-groups factor. The degree of freedom was corrected for unequal variance using the Greenhouse-Geisser correction. Differences among the groups and each group over the 6 postinjury test weeks were performed using Tukey's honestly significant difference (HSD) post hoc $t$ tests.

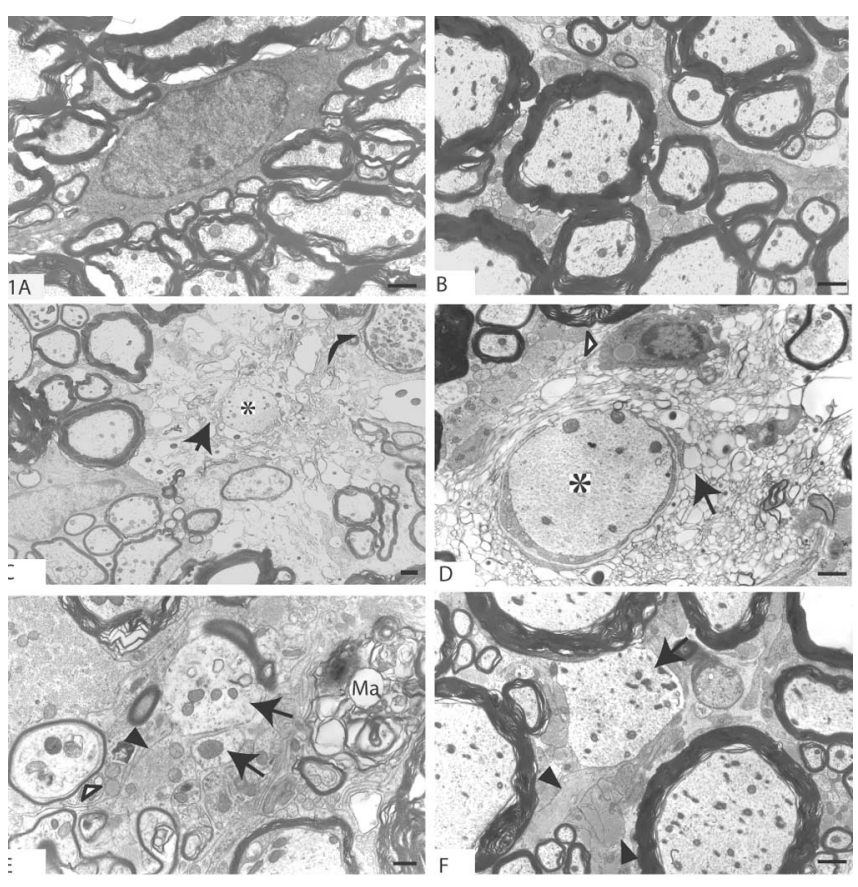

Figure 1. Demyelination after contusive SCI. $A, B$, In the VLF of normal adult spinal cord, darkly stained compact myelin, the thickness of which is proportional to axon diameter, surrounded each axon. $\boldsymbol{C}, \boldsymbol{D}, \mathrm{In}$ the VLF at 1 week after $\mathrm{SCl}$, many myelin sheaths had degenerated and numerous intramyelinic vacuoles were seen (arrows). $\boldsymbol{D}, \mathrm{A}$ macrophage was observed in close relation to degenerating myelin (open arrowhead). $\boldsymbol{C}, \mathbf{D}$, The axons surrounded by degenerating myelin appeared morphologically normal (asterisks). C, These axons could be distinguished from those that were undergoing degeneration (curved arrows). $E$, $F$, Some demyelinated axons survived for at least 1 month after injury (arrows). $\boldsymbol{E}, \boldsymbol{F}$, Healthy-appearing demyelinated axons were observed in the VLF at the injury epicenter $(\boldsymbol{E})$ and also a few millimeters away from the epicenter ( $\boldsymbol{F}$, arrow). These axons are adjacent to astrocytic processes (arrowheads). Scale bars, $2.5 \mu \mathrm{m}$.

tcMMEP responses. All tcMMEP responses were obtained from stimulation of awake, nonanesthetized, restrained rats, as described previously (Magnuson et al., 1999; Loy et al., 2002; Cao et al., 2005). Briefly, rats were placed in a prone position on a wooden board and wrapped in a cloth stockingette tacked to the board surface. The hindlimbs were pulled through the cloth and left exposed to enable the insertion of needle electrodes into the gastrocnemius muscle of each hindlimb, with the active electrode placed into the gastrocnemius muscle belly and the reference electrode placed near the distal tendon. The ground electrode was placed subcutaneously between the coil and recording electrodes. tcMMEP responses were elicited by activation of subcortical structures with an electromagnetic coil placed over the cranium. A single magnetic pulse with a stimulus intensity of $60 \mathrm{mV}$ and a gain of 500 or 5000 was used. Data from four responses measured $1 \mathrm{~min}$ apart were averaged. The onset latency to the initiation of response and amplitude were recorded. 

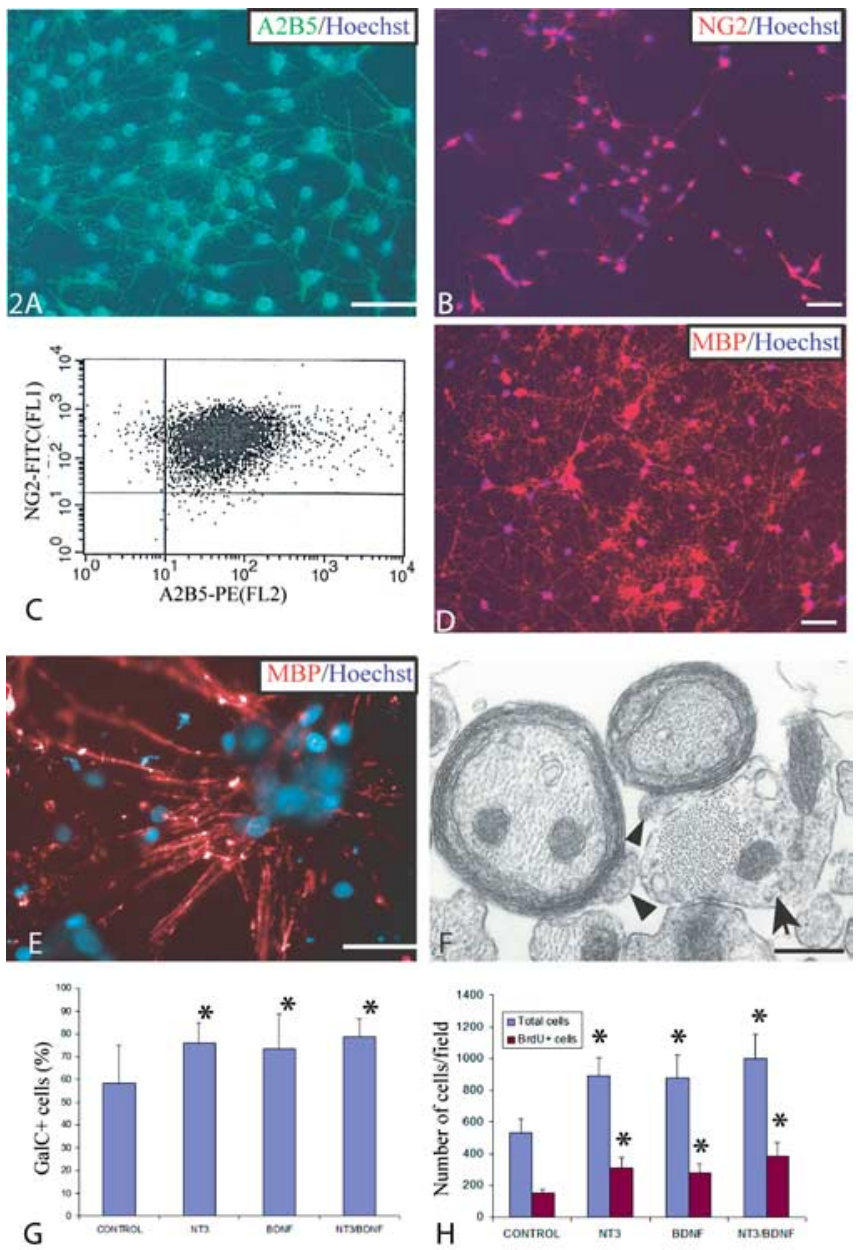

Figure 2. Differentiation of and myelination by GRPs in vitro. $\boldsymbol{A}, \boldsymbol{B}$, Proliferating GRPs expressed specific GRP markers, A2B5 (A) and NG2 (B). C, As determined by FACS analysis, $97 \%$ coexpress both markers. After differentiation for $8 \mathrm{~d}$, most GRPs became mature oligodendrocytes and expressed MBP in culture $(\boldsymbol{D})$. In coculture with DRG neurons, GRPs differentiated into mature oligodendrocytes and myelinated DRG axons as shown by MBP immunohistochemistry $(\boldsymbol{E})$. Ultrastructural analysis showed that these GRPs formed central myelin on DRG axons $(\boldsymbol{F})$. The arrowheads point to typical outer cytoplasmic loops. The arrow indicates an astrocyte process in close apposition to the oligodendrocyte myelin. G, After differentiation for $8 \mathrm{~d}$ in the presence of NT3, BDNF, or both, the percentage of galactocerebroside-positive (GalC ${ }^{+}$) oligodendrocytes increased significantly compared with the control (ANOVA single factor between groups; $F=5.509 ; \mathrm{df}=3 ; p<0.01)$. $\boldsymbol{H}, \mathrm{NT} 3$ or/and BDNF also increased the total numbers of surviving cells and $B r d U^{+}$cells after $8 \mathrm{~d}$ of differentiation. $p<0.001$. Error bars represent SEM. Scale bars: $\boldsymbol{A}, \boldsymbol{B}, \boldsymbol{D}, \boldsymbol{E}, 50 \mu \mathrm{m} ; \boldsymbol{F}, 2 \mu \mathrm{m}$.

All animals were evaluated once per week for 6 weeks. The latencies and amplitudes of tcMMEP responses over different survival times were analyzed using repeated-measures ANOVA with the between-groups factor, followed by Tukey's HSD post hoc test.

Immunohistochemistry. For the histological analysis of the grafted cells, rats were anesthetized with $80 \mathrm{mg} / \mathrm{kg}$ Nembutal and perfused transcardially with $0.01 \mathrm{M}$ PBS, $\mathrm{pH} 7.4$, followed by $4 \%$ paraformaldehyde in 0.1 $\mathrm{M}$ phosphate buffer (PB). The spinal cord segments that received the grafts were removed, cryoprotected in 30\% sucrose buffer overnight at $4^{\circ} \mathrm{C}$, and embedded in OCT compound. Some cords were transversely sectioned at $16 \mu \mathrm{m}$ on a cryostat, and others were cut longitudinally. After blocking with $10 \%$ donkey serum in Tris-buffered saline (TBS) containing $0.3 \%$ Triton X-100 (TBST) for $1 \mathrm{~h}$ at room temperature (RT), the sections were incubated in TBST containing 5\% donkey serum, polyclonal chicken anti-GFP (1:500; Chemicon, Temecula, CA), or polyclonal rabbit anti-neurofilament M (NFM) (a marker for axons; 1:200; Chemicon), with one of the following monoclonal mouse antibodies:
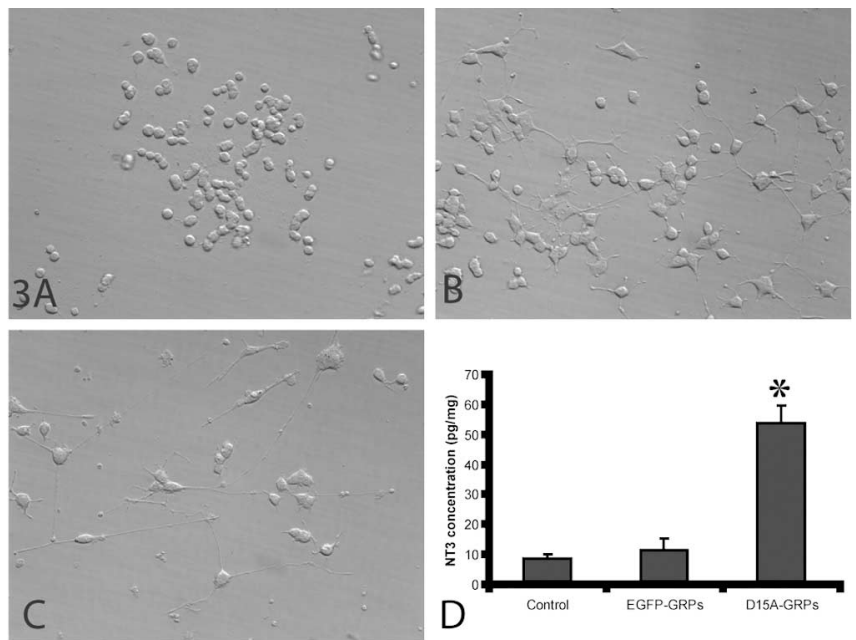

Figure 3. Secretion of NT3 by D15A-GRPs in vitro and in vivo. The bioactivity of D15A-GRPs was examined on trkC-PC12 cells. $\boldsymbol{A}$, Undifferentiated trkC-PC12 cells had round cell bodies without processes. $\boldsymbol{B}, \boldsymbol{C}$, In the presence of $10 \mathrm{ng} / \mathrm{ml} \mathrm{NT3}(\boldsymbol{B})$ or undiluted D15A-GRP conditioned medium (C), trkC-PC12 cells differentiated into multipolar neurons with several long processes. Expression of NT3 in the injured spinal cord was also examined by ELISA at 1 week after transplantation (2 weeks after injury). As shown in $\boldsymbol{D}$, expression of NT3 in rats that received grafts of D15A-GRPs is significantly higher than those that received grafts of EGFPGRPs or DMEM medium ( $\left.F=159.9 ; \mathrm{df}=2,9 ;{ }^{*} p<0.001\right)$. Data are the mean $\pm \mathrm{SD}(n=4)$.

anti-MBP (a marker for myelin; 1:200; Chemicon), anti-glial fibrillary acidic protein (GFAP) (a marker for astrocytes; 1:100; Chemicon), antiadenomatus polyposis coli (APC) (also called CC1, a marker that labels cell bodies of mature oligodendrocyte; 1:200; BD Biosciences Pharmingen, San Diego, CA), anti-NG2 (a marker for oligodendrocyte progenitor cells; 1:200; Chemicon), or anti-nestin (a marker for undifferentiated neural stem cells or progenitor cells; 1:10; Developmental Studies Hybridoma Bank) overnight at $4^{\circ} \mathrm{C}$. After three washes for $10 \mathrm{~min}$ in TBS, sections were incubated in TBST containing 5\% donkey serum, donkey anti-sheep, or donkey anti-chick FITC-conjugated Fab' fragments (1: 100; Jackson Immunoresearch, West Grove, PA), donkey anti-mouse Texas Red-conjugated $\mathrm{Fab}^{\prime}$ fragments (1:200; Jackson Immunoresearch), or donkey anti-rabbit 7-amino-4-methylcoumarin-3-acetic acid-conjugated $\mathrm{Fab}^{\prime}$ fragments (1:100; Jackson Immunoresearch) for $1 \mathrm{~h}$ at RT. The sections were rinsed in TBS and coverslipped with antifade mounting medium (Molecular Probes, Eugene, OR). A Nikon (Tokyo, Japan) Eclipse TE300 inverted fluorescence microscope equipped with Spot RT Color camera or a Zeiss (Oberkochen, Germany) Axiophot LSM 510 confocal microscope was used to capture representative images. Photomicrographs were assembled using Adobe Photoshop and Adobe Illustrator software (Adobe Systems, San Jose, CA).

Histological analyses. The total volume of spared white matter in the injured epicenter was determined as described previously (Cao et al., 2005). Briefly, after the final behavioral and physiological assessments, rats were anesthetized with an overdose of Nembutal $(80 \mathrm{mg} / \mathrm{kg})$ and perfused transcardially with $0.01 \mathrm{M}$ PBS, followed by $4 \%$ paraformaldehyde in PB, pH 7.4. Serial $20-\mu \mathrm{m}$-thick sections through the entire injury site were cut transversely on a cryostat. Two sets of slides (every ninth and 10th section, each set containing serial sections spaced $200 \mu \mathrm{m}$ apart) were stained with Luxol fast blue and cresyl violet, respectively, to identify myelinated white matter and residual spared tissue. The lesion epicenter was defined as the section containing the least amount of spared white matter. White matter sparing was defined as tissue showing normal myelin appearance and density (lacking cysts, degeneration). Septae or fibrous bands of tissue observed within and/or spanning areas of cystic cavitation were not considered to represent spared tissue. The total crosssectional area of the spinal cord and the lesion boundary were measured with an Olympus (Tokyo, Japan) BX60 microscope attached to a Neurolucida system (MicroBrightField, Colchester, VT). An unbiased esti- 

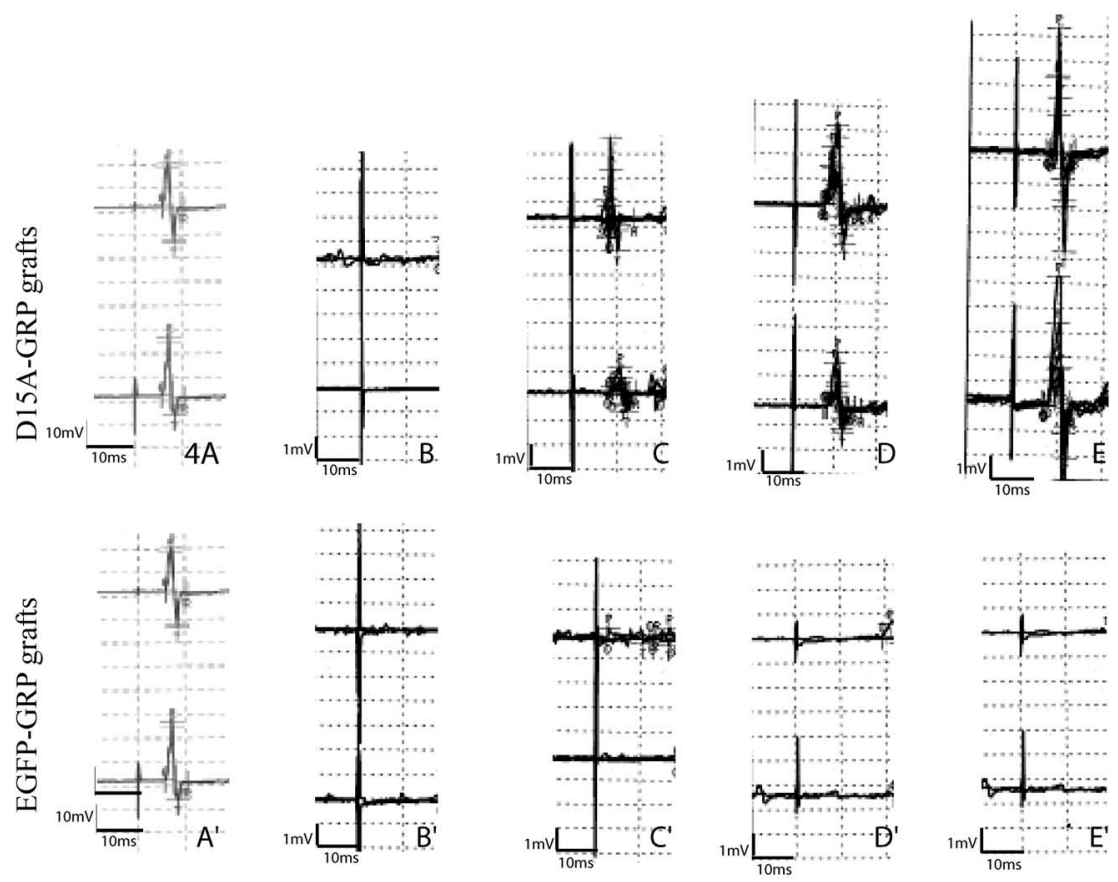

Pre-injury 1w post-graft
$3 w k s$ post-graft

5 wks post-graft
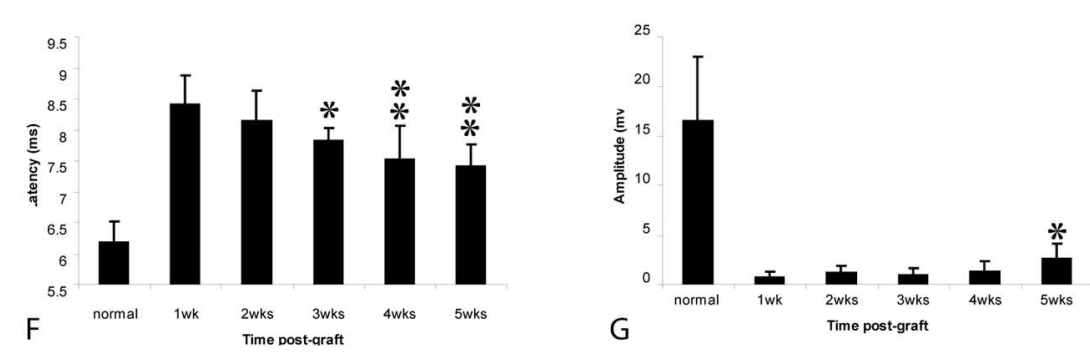

Figure 4. Electrophysiological recovery after engraftment of D15A-GRPs. In the normal adult rat, the latency of the monosynaptic tcMMEP response was $6.2 \pm 0.3 \mathrm{~ms}$ with the amplitudes ranging from 9 to $12 \mathrm{mV}$ (Fig. $3 A, A^{\prime}, F, G$ ). $\boldsymbol{B}, \boldsymbol{B}^{\prime}$, The tcMMEP responses disappeared after moderate (150 kdyn) contusion injury. C, G, At 1 week after transplantation, tcMMEP responses were partially restored, although the amplitudes were still small. $\boldsymbol{D}, \boldsymbol{E}, \mathbf{G}$, Over the 4 week survival time, the amplitude of tcMMEP responses continued to increase. Note the 10 -fold difference in gain between the recordings in $\boldsymbol{A}$ and $\boldsymbol{A}^{\prime}$ and those in $\boldsymbol{B}-\boldsymbol{E}^{\prime} . \boldsymbol{B}^{\prime}-\boldsymbol{E}^{\prime}$, In control animals, the restoration of tcMMEP responses was never observed. $\boldsymbol{F}$, Latencies of the recovered tCMMEP responses shortened after D15A-GRP engraftment. Repeated ANOVA measures showed that latencies were significantly different over survival time $(F=7.0 ; \mathrm{df}=4,24 ; p<0.05)$. Tukey's HSD post hoc $t$ tests showed that latencies of recovered tcMMEP responses decreased significantly by weeks $3\left({ }^{*} p<0.05\right), 4$, and $5\left({ }^{* *} p<0.01\right)$, compared with 1 week after graft. Latencies on weeks 4 and 5 were also significantly shorter than those in week $2(p<0.05)$. All latencies in D15A-GRP-grafted animals were significantly longer than those in normal uninjured animals. $G$, Repeated-measures ANOVA showed that the amplitudes of recovered tcMMEP responses $(\boldsymbol{G})$ changed significantly over the survival time $(F=5.9 ; \mathrm{df}=4,24 ; p<0.005)$. Turkey's HSD post hoc $t$ test showed that amplitudes in week 5 after graft were significantly higher than those in all other weeks (week 5 vs weeks 1 and $3, p<0.01$; week 5 vs weeks 2 and $4, p<0.05$ ). Error bars represent SEM.

mation of the percentage of spared tissue was calculated using the Cavalieri method. The total volume of spared white and lesion area was calculated by summing their individual subvolumes (Oorschot, 1994). Individual subvolumes of lesion area and spared tissue were calculated by multiplying the cross-sectional area $(A)$ by $D$, where $D$ represents the distance between sections $(200 \mu \mathrm{m})$. The percentage of spared white matter and injured areas were calculated by dividing the total volume of spared white matter and lesion area by the total WM volume and spinal cord volume, respectively. Mean values of percentage of lesion area and spared WM among different injured groups were calculated and statistically compared using one-way ANOVA followed by Tukey's post hoc testing.

Quantitation of APC-positive engrafted GRPs. Four coronal sections, $200 \mu \mathrm{m}$ apart, were taken spanning the lesion epicenter. The percentage of engrafted GRPs (either EGFP- or D15A-infected, identified by EGFP expression) that coexpressed APC was quantified for the two groups of grafted animals. For ratio analysis, unbiased stereological counting methods are not needed (Coggeshall and Lekan, 1996).

Electron microscopy. To study demyelination in the contused ventrolateral funiculus (VLF), which is important for locomotor function and also conducts tcMMEP responses (Loy et al., 2002; Schucht et al., 2002; Cao et al., 2005), normal control or $150 \mathrm{kdyn}$-injured rats at 1 week or 1 month after injury were perfused intracardially with saline, followed by $2 \%$ glutaraldehyde and $4 \%$ paraformaldehyde in $0.1 \mathrm{~m}$ sodium cacodylate buffer, $\mathrm{pH}$ 7.4. Immediately after perfusion, spinal cords were removed and postfixed in the same fixative overnight at $4^{\circ} \mathrm{C}$. The spinal cord segment at the injury epicenter was sliced into $1 \mathrm{~mm}$ pieces, postfixed for $2 \mathrm{~h}$ in $1 \% \mathrm{OsO}_{4}$ in $0.1 \mathrm{~m}$ cacodylate buffer, dehydrated in graded ethanol solutions, and embedded in Epon 812 (Ernest Fullam, Latham, NY). One micrometer semithin plastic sections were cut and stained with $1 \%$ toluidine blue before examination in a Nikon Eclipse TE300 microscope equipped with a Spot RT Color CCD camera. The VLF at the injury epicenter, where demyelination was observed by light microscopy, and the corresponding area in the shamoperated controls, were trimmed to an area of $1 \times 2 \mathrm{~mm}^{2}$ for thin sectioning. The VLF was chosen for analysis because this area contains pathways that are responsible for tcMMEP responses (Loy et al., 2002; Cao et al., 2005). For EM, cross sections of the VLF were stained with uranyl acetate and lead citrate and examined using a Philips (Aachen, Germany) CM10 transmission electron microscope. Ultrastructural analysis of GRP-DRG neuron cultures was done exactly as described previously (Plant et al., 2002).

Immunocytochemistry for electron microscope. For immuno-EM, rats were perfused with the same perfusion fixatives as those described above for immunohistochemistry, but with the addition of $0.1 \%$ glutaraldehyde. After perfusion, the spinal cord was carefully dissected out and blocked into proximal (injured epicenter) and distal ( $8 \mathrm{~mm}$ away from the epicenter) segments in both caudal and rostral directions. Horizontal sections were cut at 30 $\mu \mathrm{m}$ on a vibratome. The sections were subjected to immunohistochemical processing for EGFP using the avidin-biotin peroxidase complex (ABC) method. Briefly, sections were blocked in $10 \%$ goat serum in $0.01 \mathrm{~m}$ PBS containing $0.05 \%$ Triton X-100 for $30 \mathrm{~min}$ at RT and then incubated with polyclonal chicken anti-EGFP antibody (1:2000; Chemicon) containing $3 \%$ goat serum for $24 \mathrm{~h}$ at $4^{\circ} \mathrm{C}$ After several rinses in $0.01 \mathrm{M}$ PBS, the sections were reacted with biotinylated goat anti-chicken IgG (1:200; Vector Laboratories, Burlingame, CA) for $1 \mathrm{~h}$ and subsequently with Vector ABC reagent (1:200; Vector Laboratories) for $1 \mathrm{~h}$ at RT. The reaction product was revealed by incubation for 5-10 min with $0.05 \%$ diaminobenzidine tetrahydrochloride and $0.01 \% \mathrm{H}_{2} \mathrm{O}_{2}$ in $0.05 \mathrm{M}$ Tris- $\mathrm{HCl}, \mathrm{pH}$ 7.6. After reaction, the sections were postfixed in $1 \%$ osmium tetroxide in $0.1 \mathrm{~m} \mathrm{~PB}, \mathrm{pH} 7.4$, for $1 \mathrm{~h}$ at RT and dehydrated in graded ethanols and propylene oxide. The sections were then flat embedded in Epon on slides. After cutting, sections were examined, and the VLF was cut out and glued to Epon cylinders for ultrathin sectioning. The ultrathin sections were mounted on grids and 
examined and photographed using a Philips CM10 transmission electron microscope.

\section{Results}

\section{Demyelination in contusion SCI}

We first determined whether demyelinated axons would survive in the contused VLF, where tcMMEP responses are conducted (Loy et al., 2002; Cao et al., 2005). In the normal spinal cord, axons in the VLF appeared as round or slightly oval profiles with varying diameter. A darkly stained rim of compact myelin, whose thickness was proportional to the axon diameter, surrounded each axon (Fig. $1 A, B$ ). One week after injury, the most evident pathological change in the VLF myelin was the presence of vacuoles (Fig. $1 C, D$, arrows) as the myelin layers separated. Macrophages and/or microglia observed close to the degenerating myelin contained phagocytosed material (Fig. 1D, arrowhead). Importantly, many demyelinated axons appeared morphologically normal (Fig. 1C,D, asterisks), although some showed axoplasmic organelle condensation, suggesting axonal degeneration (Fig. 1C, curved arrowhead). One month after injury, the number of demyelinated axons in the VLF decreased compared with 1 week after injury. However, many healthy-appearing demyelinated axons were still evident (Fig. $1 E, F$, arrows), and they were in close apposition to astrocytic processes (Fig. $1 E, F$, arrowheads). Some axons were wrapped by thin myelin relative to their axonal diameters (Fig. $1 E$, open arrowhead), suggesting remyelination. Thus, ultrastructural analysis demonstrated that demyelination occurred in the VLF after contusive SCI, and some of these demyelinated axons could survive for at least 1 month after injury.

\section{Differentiation of and myelination by GRPs in vitro}

Proliferating, passage 2 GRPs stained with antibodies directed against A2B5 and the GRP-specific chondroitin sulfate proteoglycan NG2 (Fig. 2A,B); 97\% coexpressed both markers (Fig. $2 C), \sim 6 \%$ of these cells expressed the bipotential oligodendrocyte/astrocyte precursor marker $\mathrm{O} 4$ (data not shown), and none expressed the more mature oligodendrocyte markers O1, RIP (receptor-interacting protein), or MBP, or the astrocyte-specific proteins GFAP or vimentin (data not shown). After $8 \mathrm{~d}$ in culture, in the absence of FGF2 and PDGFaa, but in the presence of T3, $>80 \%$ of the cells matured to express MBP (Fig. 2D). When cultured in medium containing $10 \%$ FBS, $>50 \%$ of the cells developed into $\mathrm{GFAP}^{+}$astrocytes (data not shown). No neurons were observed under any differentiating conditions. Thus, the purified GRPs were bipotential and could differentiate into both oligodendrocytes and astrocytes.

To test the capacity of GRPs to myelinate axons, we cocultured GRPs with purified embryonic DRG neurons (Plant et al., 2002). After coculture for 4 weeks, numerous GRPs were observed to myelinate the DRG axons as assessed by MBP expression (Fig. $2 E$ ). Ultrastructural analysis of the myelin formed by these GRPs showed it to be CNS myelin (Fig. 2F). GRP-derived astrocyte processes were in close apposition to these myelinated axons (Fig. $2 F$, arrow). These in vitro studies demonstrated that the isolated GRPs differentiated into mature astrocytes and oligodendrocytes, the latter forming CNS-type myelin.

To study the effect of NT3 and BDNF on GRP maturation, we differentiated the GRPs in vitro in the absence of FGF2 and PDGFaa but in the presence of NT3, BDNF, or both. After differentiation for $8 \mathrm{~d}$, the percentage of galactocerebroside-positive cells was significantly increased in the presence of NT3, BDNF, or both (Fig. $2 G$ ), indicating that the differentiation into oligoden-

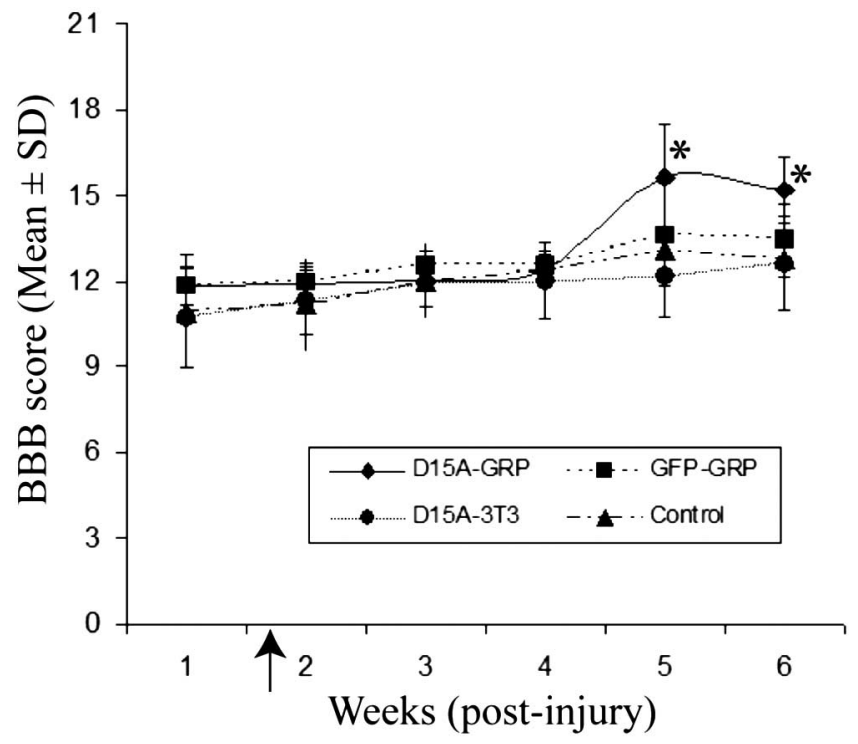

Figure 5. Locomotor recovery after transplantation of D15A-GRPs. Repeated-measures ANOVA showed that BBB scores were significantly different between groups $(F=5.2 ; \mathrm{df}=$ $3,40 ; p<0.05)$, and they also changed significantly over survival time $(F=50.8 ; \mathrm{df}=3126$ $p<0.001$ ). Tukey's HSD post hoc t tests showed that BBB scores in D15A-GRP-grafted animals were significantly higher than those in control, EGFP-GRPs, or D15A-NIH3T3 animals (all $p<$ 0.05). There were no significant differences of $B B B$ scores between the groups from week 1 to week 4 after injury. BBB scores were significantly improved at weeks 5 and 6 compared with week 1 after injury in all four groups ( ${ }^{*}$ all $p<0.05$ ). The arrowhead on the abscissa indicates the time of transplantation. Data are the mean \pm SD $(n=11)$.

drocytes was enhanced by NT3 and BDNF. NT3 had been shown previously to be important for the survival and proliferation of oligodendrocytes in vivo (Barres et al., 1994). We then determined whether NT3 and/or BDNF affected the number of surviving and proliferating GRPs during their differentiation. After differentiation for $8 \mathrm{~d}$, the total number of cells was significantly increased in the presence of either NT3, BDNF, or both (Fig. $2 H$ ). To determine whether the increase was attributable to enhanced proliferation, dividing cells were labeled with BrdU for $24 \mathrm{~h}$ on day 8 after differentiation in the presence or absence of neurotrophins. The number of BrdU ${ }^{+}$cells was significantly increased in the presence of NT3, BDNF, or both (Fig. $2 H$ ). Thus, NT3 and BDNF enhanced the survival, proliferation, and differentiation of GRPs into oligodendrocytes in vitro.

\section{Electrophysiological and locomotor functional recovery after engraftment of GRPs}

We next asked whether the combination of GRP transplantation and neurotrophin delivery could restore electrophysiological conduction after demyelination and, more importantly, enhance the recovery of hindlimb locomotor function after SCI. Before engraftment, GRPs were infected with a retrovirus encoding EGFP or D15A-EGFP. Additional groups of injured animals were grafted with D15A-infected NIH3T3 cells or injected with 4 $\mu \mathrm{l}\left(10^{9} \mathrm{pfu}\right)$ of an adenovirus encoding D15A or DMEM. We first used trkC-PC12 cells (Tsoulfas et al., 1993) to detect the secretion and bioactivity of D15A-GRPs in vitro. As shown in Figure $3 A$, undifferentiated trkC-PG12 cells had a round cell body without any obvious processes. After growth in the presence of NT3 (Fig. $3 B$ ) or D15A condition medium (Fig. $3 C$ ) for $3 \mathrm{~d}$, trkC-PC12 cells became multipolar cells with several elongated processes. The percentage of differentiated trkC-PC12 cells were 8.1, 10.6, $15.5,18.7,20.6,25$, and $34.8 \%$, respectively, in the presence of 

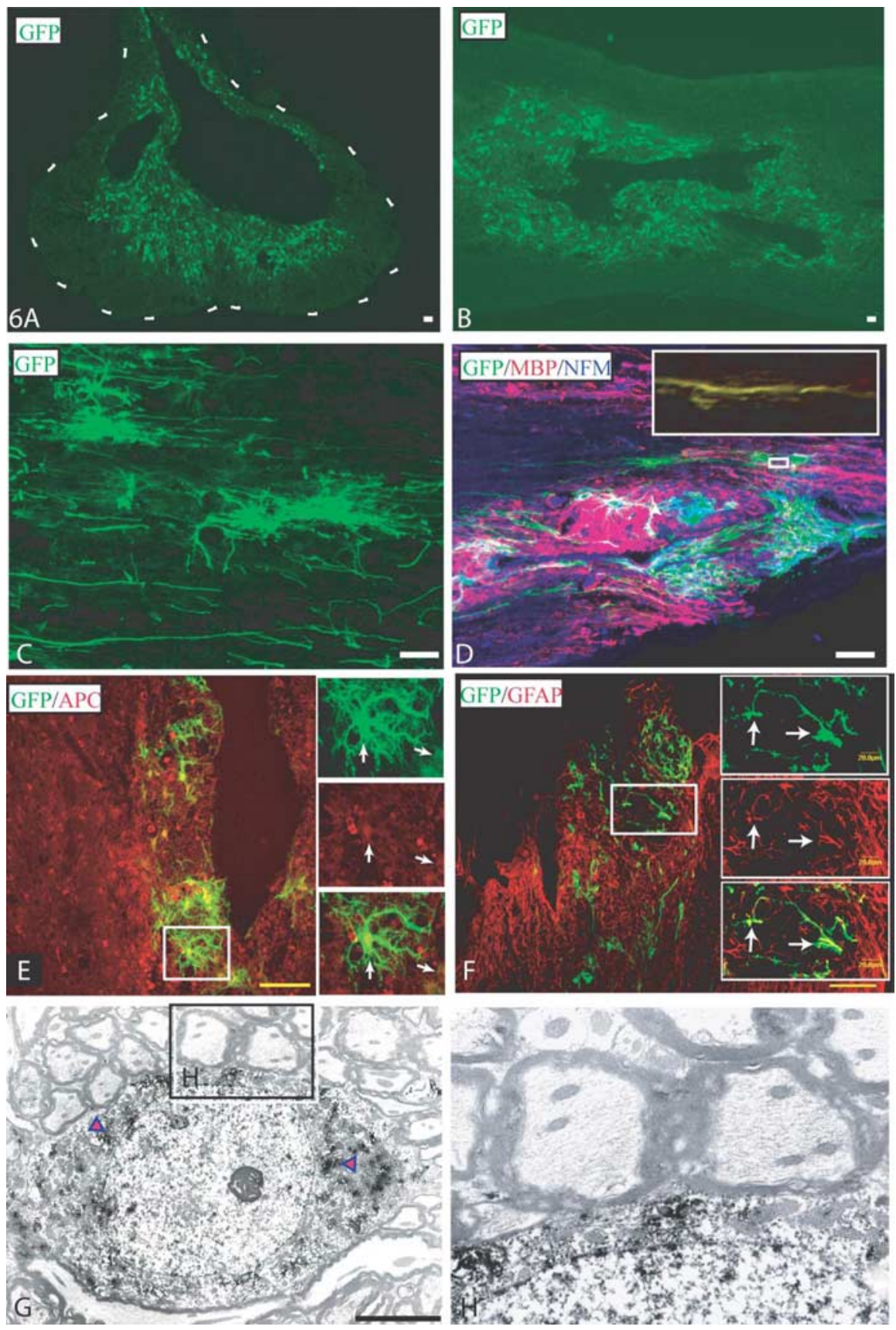

Figure 6. Survival and differentiation of D15A-GRP-grafted into the contused spinal cord. $\boldsymbol{A}-\boldsymbol{C}$, At 6 weeks after graft, robust survival of grafted cells was observed in the injury epicenter with most cells in the ventral spinal cord $(\boldsymbol{A})$. The dashes in $\boldsymbol{A}$ outline the boundary of the spinal cord. $\boldsymbol{B}, \boldsymbol{C}$, Low $(\boldsymbol{B})$ and high $(\boldsymbol{C})$ magnification of horizontal images show that the grafted cells migrate widely and extend long processes along the axis of the spinal cord. $\boldsymbol{D}$, Many grafted D15A-GRPs differentiated into MBP ${ }^{+}$ oligodendrocyte-like cells with multiple processes closely apposing NFM ${ }^{+}$axons. The boxed region in $\boldsymbol{D}$ is shown at higher magnification in the insert. $\boldsymbol{E}, \boldsymbol{F}$, Many grafted D15A-GRPs differentiated into mature oligodendrocytes expressing APC (E) and others into GFAP ${ }^{+}$astrocytes $(\boldsymbol{F})$. The boxes in $\boldsymbol{E}$ and $\boldsymbol{F}$ are shown at higher magnification in the insets. $\boldsymbol{G}, \boldsymbol{H}$, Ultrastructural analysis shows a GRP-derived mature oligodendrocyte near newly formed central myelin sheaths. Note that EGFP immunoproducts are clearly seen within the cytoplasm (arrowheads) of this cell, confirming its origin from an engrafted GRP. Scale bars: $\boldsymbol{A}-\boldsymbol{D}$, $50 \mu \mathrm{m} ; \boldsymbol{E}, \boldsymbol{F}, 100 \mu \mathrm{m} ; \boldsymbol{G}, 2 \mu \mathrm{m}$.

NT3 at concentrations of $0.25,0.5,1,2,4,6$, and $10 \mathrm{ng} / \mathrm{ml}$. The percentage of differentiated trkC-PC12 cells as $26.5 \%$ in the undiluted D15A-GRPs conditioned medium, which was equal to the bioactivity of NT3 at $6.43 \pm 0.48 \mathrm{ng} / \mathrm{ml}$ determined by the recombinant human NT3 standard curve of trkC-PC12 cells. Our ELISA assay showed that D15A-GRP conditioned medium had $6.54 \pm 0.05 \mathrm{ng} / \mathrm{ml}$ (mean $\pm \mathrm{SD} ; n=3)$ NT3, which con- firmed the secretion of NT3 into D15AGRP conditioned medium. No NT3 was detected in DMEM or EGFP-GRP conditioned medium by either bioactivity or ELISA assay. These results showed that D15A-GRPs secreted biologically active D15A into the culture medium. We also used an ELISA assay to examine whether D15A-GRPs could stably secret D15A into the injured spinal cord. As shown in Figure $3 D$, expression of NT3 in animals that received grafts of D15A-GRPs $(53.7 \pm 5.8 \mathrm{pg} / \mathrm{mg})$ was significantly higher compared with ones that received grafts of EGFP-GRPs $(11.6 \pm 3.6 \mathrm{pg} / \mathrm{mg})$ or DMEM $(8.8 \pm 1.2 \mathrm{pg} / \mathrm{mg})$ at 1 week after transplantation (2 weeks after injury). These results demonstrate that D15A-GRPs secreted D15A into the injured spinal cord.

Because tcMMEP responses provide a reproducible, noninvasive, and objective assessment of axonal conduction and functional integrity of descending VLF motor pathways in both normal and injured spinal cord (Fehlings et al., 1987; Loy et al., 2002), they were used to monitor the electrophysiological function of VLF axons after grafting. In the normal adult rat, the latency of the monosynaptic tcMMEP response was $6.2 \pm 0.3 \mathrm{~ms}$ and the amplitudes of this normal response ranged from 9.0 to $21.0 \mathrm{mV}$, with an average of $16.0 \pm 3.8 \mathrm{mV}$ (Loy et al., 2002; Cao et al., 2005) (Fig. 4A, $A^{\prime}$ ). After a $150 \mathrm{kdyn}$ contusive SCI, tcMMEP responses disappeared (Fig. $4 B, B^{\prime}$ ). One week after transplantation of D15A-GRPs, tcMMEP responses were partially restored in 8 of 12 rats; however, the latencies $(8.41 \pm 0.46$ ms) were significantly longer $(p<0.001)$, and the amplitudes $(0.7 \pm 0.6 \mathrm{mV})$ were significantly smaller $(p<0.001)$ than in normal animals (Fig. $4 C, F, G$ ). Note the 10 -fold difference in gain between the recordings in Figure 4, $A$ and $A^{\prime}$ and those in $B, B^{\prime}-E, E^{\prime}$. The latencies of tcMMEP responses in D15A-GRP transplanted animals continued to become shorter over time (Fig. $4 D-F$ ). The latencies at 2 and 3 weeks after graft were $8.14 \pm 0.48$ and $7.81 \pm 0.22 \mathrm{~ms}$, respectively. The latencies at week 3 after graft were significantly shorter compared with week 1 after graft $(p<0.01)$ but were still significantly longer than the latencies in normal animals. At weeks 4 and 5 after grafting, the latencies dropped to $7.52 \pm 0.56$ and $7.41 \pm 0.36 \mathrm{~ms}$, which were significantly shorter than at weeks 1 and 2 after grafting (all $p<0.05$ ) but were still significantly longer than in normal animals $(p<0.01)$. Although there was a strong trend for mean amplitudes of the returned tcMMEP to increase from week 1 to week 4 after grafting $(0.67 \pm$ $0.59 \mathrm{mV}$ in week $1,1.13 \pm 0.71 \mathrm{mV}$ in week $2,0.95 \pm 0.68 \mathrm{mV}$ in 
week 3 , and $1.33 \pm 1.02 \mathrm{mV}$ in week 4 , respectively), they were not significantly different from each other (Fig. 4G). However, the amplitudes in week 5 postgraft animals $(2.57 \pm 1.56 \mathrm{mV})$ were significantly higher than in weeks $1-4$ after graft $(p<0.05)$ (Fig. $4 G$ ). In the animals that received EGFP-GRPs (Fig. $4 C^{\prime}-E^{\prime}$ ), D15A-NIH3T3 cells, D15A adenovirus, or DMEM injection (data not shown), the return of tcMMEP responses was never observed. The D15A adenovirus was used as a control for D15A expression in the absence of an exogenous cellular graft. Thus, the conduction of tcMMEP responses through the initially demyelinated axons in the VLF was partially restored only by the transplantation of D15A-GRPs.

We further asked whether the electrophysiological restoration of tcMMEP responses correlated with improvement of hindlimb locomotor function. Consistent with our (Cao et al., 2005) and other (Scheff et al., 2003) published reports, in 150 kdyn-injured animals, BBB scores were improved over time in each group (Fig. $5)$. BBB scores were significantly higher at week 5 and $6(p<$ $0.01)$ than at week 1 after injury in all four groups. More importantly, BBB scores in D15A-GRP-grafted animals were 15.6 and 15.2 at 4 and 5 weeks after graft, respectively, which were significantly higher than those for the D15A-NIH3T3 cell-grafted group (12.2 and 12.6), or the DMEM-injected animals (13.1 and 12.7), respectively (all $p<0.05$ ) (Fig. 5). Although there was a trend for greater improvement of BBB scores in EGFP-GRPgrafted animals at 4 and 5 weeks after transplantation, respectively, this improvement over D15A-NIH3T3 cell-grafted and DMEM-injected animals did not reach statistical significance. BBB scores among the four groups were not significantly different from week 1 to week 4 after injury. Therefore, our behavioral results were consistent with the electrophysiological data; significant enhancement of hindlimb function was only observed in the D15A-GRP-grafted animals starting at 5 weeks after injury (4 weeks after transplantation).

\section{Differentiation of engrafted GRPs in the injured spinal cord}

We next addressed whether the functional recovery in the D15AGRP-grafted animals was potentially mediated by remyelination. Six weeks after grafting, robust survival of transplanted GRPs was observed in D15A-GRP-grafted animals (Fig. 5A-C) and also in EGFP-GRP-grafted animals (data not shown) with cells distributed around the cavities throughout the injury site. Many more grafted cells were localized in the ventral than dorsal spinal cord, likely because of the increased spared white matter in the ventral spinal cord (Fig. 6A) and the VLF graft location. The grafted cells migrated widely, up to $4 \mathrm{~mm}$ rostrocaudally in the white matter. In longitudinal sections, D15A-GRP processes could be traced by EGFP immunohistochemistry several millimeters along the axons (Fig. 6C). Many engrafted D15A-GRPs showed typical oligodendrocyte morphology with multiple processes closely apposing $\mathrm{NFM}^{+}$axons (Fig. $6 \mathrm{D}$ ).

To determine the maturation state of the grafted D15A-GRPs, cells were double stained with EGFP and mature oligodendrocyte markers MBP and APC. As shown in Figure 6D, grafted GRPs express $\mathrm{MBP}^{+}$myelin with the long $\mathrm{EGFP}^{+} / \mathrm{MBP}^{+}$processes apposing the longitudinal axons in the white matter, suggesting that some grafted D15A-GRP formed mature myelin. Many grafted GRPs expressed APC (Fig. 6E). Although APC has been reported previously to label Schwann cells in addition to oligodendrocytes after SCI (McTigue et al., 2001), we did not observe colabeling with APC and the Schwann cell marker S-100 $\beta$ (data not shown). The light microscopic results were confirmed by EGFP-immunohistochemical EM that showed that the grafted
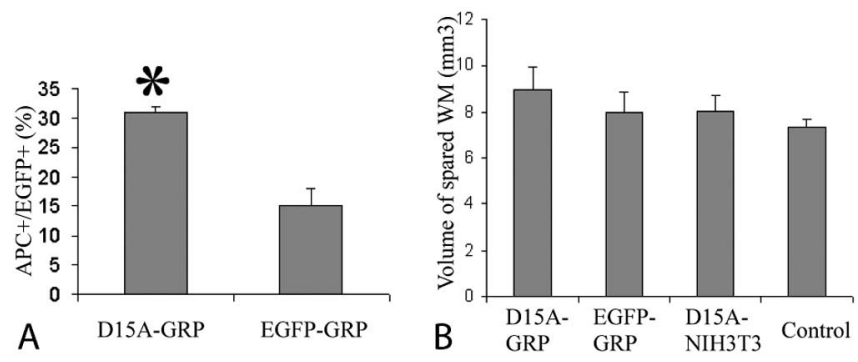

Figure 7. Quantification of oligodendrocytic differentiation and spared WM. $\boldsymbol{A}$, The percentage of $A P C^{+}$oligodendrocytes was significantly higher in the animals grafted with D15A-GRPs than with EGFP-GRPs (mean $\pm \mathrm{SEM} ; n=4 ;{ }^{*} p<0.01$ ), consistent with our in vitro data. $\boldsymbol{B}$, The total volume of spared white matter at the injury epicenter ( $4 \mathrm{~mm}$ rostrocaudal from the injury) was not significantly increased between animals receiving D15A-GRPs, EGFP-GRPs, D15A-NIH3T3 cells, or DMEM (mean \pm SEM; ANOVA; $F=3.099 ; \mathrm{df}=3 ; p=0.064$ ).

D15A-GRPs were in the areas of new central myelin sheaths in the VLF (Fig. 6G,H). To examine whether D15A expression enhanced GRP differentiation in vivo, the percentages of $\mathrm{EGFP}^{+}$ cells expressing APC were counted in the D15A-GRP and EGFPGRP-grafted groups. The percentage of $\mathrm{APC}^{+}{ }^{+}$-grafted GRPs was more than twofold greater in the D15A-GRP-grafted animals (Fig. 7A). These data were consistent with the in vitro results and suggested that BDNF and NT3 enhanced the survival, differentiation, and myelination of grafted GRP-derived oligodendrocytes in vivo. Many grafted GRPs still expressed NG2, an oligodendrocyte precursor marker, suggesting that many of the grafted cells remain undifferentiated (data not shown). Some of the grafted $\mathrm{EGFP}^{+}$GRPs became GFAP $^{+}$astrocytes (Fig. $5 F$ ) with morphologies distinct from the oligodendrocytes just described above. These cells usually had small cell bodies with fewer processes.

We finally asked whether the functional recovery observed in the D15A-GRP-grafted animals might also be attributable, in part, to increased sparing of white matter as a result of the presence of D15A. The total volume of spared white matter in $4 \mathrm{~mm}$ of the spinal cord rostral and caudal to the injury epicenter was $8.92 \pm 1.05,7.96 \pm 0.9,8.06 \pm 0.66$, and $7.38 \pm 0.29 \mathrm{~mm}^{3}$ in animals receiving D15A-GRPs, EGFP-GRPs, D15A-NIH3T3 cells, or DMEM, respectively. The differences among these values were not statistically different (Fig. $7 B$ ). Thus, the functional recovery observed in D15A-GRP-grafted animals resulted mainly from successful remyelination, with no apparent increase in white matter sparing.

\section{Discussion}

In this study, we showed that many demyelinated but otherwise intact axons exist in the VLF after contusive SCI and that the demyelinated axons survived for at least 1 month after the injury. These results are consistent with previous histological studies showing that there is chronic demyelination of axons after traumatic SCI in both humans (Bunge et al., 1993; Guest et al., 2005) and experimental animals (Blight, 1983, 1993; Cao et al., 2005; Totoiu and Keirstead, 2005). Electrophysiological analyses showed that the normal tcMMEP responses are absent after SCI, and such conduction deficits persist chronically, also consistent with findings in the injured human (Alexeeva et al., 1997, 1998) and rodent (Blight, 1993) spinal cord. Mitotically competent OPCs are harbored in the adult spinal cord (Horner et al., 2000) and proliferate after SCI (Ishii et al., 2001; McTigue et al., 2001; Yamamoto et al., 2001). These cells have the potential to differentiate into oligodendrocytes in vitro (Engel and Wolswijk, 1996) 
and in vivo (Gensert and Goldman, 1997). However, the persisting conduction deficits after traumatic SCI indicate that endogenous oligodendrocytes and/or OPCs fail to fully remyelinate the demyelinated axons and restore electrophysiological conduction. Because massive oligodendrocyte death attributable to apoptosis occurs acutely after SCI, with some oligodendrocyte death observed a few segments away from the injury epicenter (Crowe et al., 1997; Liu et al., 1997; Springer et al., 1999), it is likely that endogenous OPCs are unable to completely restore lost myelin in the injured spinal cord. Endogenous remyelination in the chemically demyelinated adult rat VLF is predominantly by invading Schwann cells, but is incapable of chronically restoring tcMMEP responses (Talbott et al., 2005). Increasing the number of cells with the ability to differentiate into oligodendrocytes by transplantation may be one very important means for replacing lost myelin. However, transplantation of EGFP-GRPs did not restore tcMMEP responses in the contused spinal cord, suggesting that increasing the number of GRPs alone is not enough to restore the function of demyelinated axons and that additional factors are required.

We observed that many grafted GRPs either remained undifferentiated $\left(\mathrm{NG}^{2+}\right)$ or differentiated into astrocytes, with only a small number of cells $(\sim 12 \%)$ differentiating into $\mathrm{APC}^{+}$oligodendrocytes. These data suggest that full oligodendrocyte differentiation of the grafted GRPs is restricted and is consistent with previous studies that showed that oligodendrocyte differentiation of exogenous GRPs is restricted after traumatic SCI (Han et al., 2004; Hill et al., 2004). We showed recently that, after demyelination of the VLF by injection of the glial toxin ethidium bromide, which kills both oligodendrocytes and astrocytes, the number of endogenous OPCs increases, and these proliferating OPCs express two transcription factors important in oligodendrocyte development, Nkx2.2 and Olig2 (Talbott et al., 2005). However, mature oligodendrocyte differentiation of these proliferating endogenous OPCs is restricted. Previous studies showed that the differentiation of multipotent neural stem cells engrafted into the normal or contusive spinal cord is restricted to an astrocytic lineage, although these neural stem cells have the potential to differentiate into oligodendrocytes, neurons, and astrocytes in vitro (Chow et al., 2000; Shihabuddin et al., 2000; Cao et al., 2001; Hill et al., 2004; Hofstetter et al., 2005). Together, these studies suggest that the microenvironment in the injured spinal cord may be inhibitory for full oligodendrocyte differentiation from endogenous and/or grafted GRPs. The factor(s) responsible for this inhibition remain to be determined. Induction of NSCs or GRPs along the oligodendrocyte lineage before transplantation may be one effective approach for enhancing oligodendrocyte differentiation in the injured spinal cord (Liu et al., 2000; Keirstead et al., 2005). Expression of growth factors that promote oligodendrocyte differentiation and maturation may also increase remyelination in the injured spinal cord (McTigue et al., 1998; Bambakidis and Miller, 2004).

It is possible that a lack of trophic factors necessary for oligodendrocyte maturation in the injured spinal cord may result in the failure of endogenous OPCs and grafted GRPs to fully differentiate into myelinating oligodendrocytes after SCI. Transplantation of fibroblasts, genetically modified to secrete NT3, into the contused spinal cord of rats increases myelination by endogenous OPCs (McTigue et al., 1998). However, present data showed that administration of D15A alone, by either transplantation of D15A-expressing fibroblasts or the injection of an adenovirus encoding D15A into the injured spinal cord, failed to result in the recovery of tcMMEP responses or enhanced hindlimb locomotor function. This result suggests that increasing remyelination by endogenous OPCs by administration of neurotrophins alone is insufficient to remyelinate enough demyelinated axons to facilitate electrophysiological and behavioral recovery. This may reflect the fact that the number of endogenous OPCs in the adult spinal cord is limited (Sim et al., 2002). As discussed above, transplantation of EGFP-GRPs alone is also not enough to facilitate functional recovery after SCI.

In these experiments, only the transplantation of D15A-GRPs into the injured spinal cord restored tcMMEP responses and hindlimb locomotor function. Histological analysis showed that the grafted D15A-GRPs differentiated into $\mathrm{MBP}^{+}$oligodendrocytes in the injured spinal cord, and EM analysis confirmed that the grafted D15A-GRPs formed central myelin around the axons. Quantitation of white matter sparing at the lesion epicenter, however, showed no difference between the D15A-GRP-grafted group and the other groups, including EGFP-GRP and D15ANIH3T3 grafts, indicating that with D15A-GRP grafts, functional recovery was likely attributable to the enhanced remyelination by grafted GRPs of spared or regenerated axons. In vitro experiments showed that NT3 and BDNF increased the proliferation and survival of differentiating GRPs supporting similar mechanism(s) in vivo. Consistent with this interpretation, delivery of neutralizing NT3 antibodies to the developing optic nerve significantly reduced the number of oligodendrocytes (Barres et al., 1994). NT3 also enhanced the survival and proliferation of oligodendrocyte lineage cells in culture (Barres and Raff, 1994; Yan and Wood, 2000). Oligodendrocytic differentiation of the grafted D15A-GRPs was twofold greater than that seen with EGFP-GRPs, consistent with in vitro oligodendrocyte differentiation data. Myelination by GRPs of cultured neurons was significantly increased by NT3 (Yan and Wood, 2000; Rubio et al., 2004). D15A most likely promotes remyelination by directly enhancing the differentiation and myelination capacity of endogenous and grafted GRPs.

It is also possible the D15A-expressing GRPs enhance the regeneration of some axons after SCI because BDNF and NT3 can facilitate regeneration of numerous supraspinal pathways involved in locomotion (Onifer et al., 2000). Astrocytic differentiation of the engrafted GRPs could provide a permissive substrate for regeneration (Privat, 2003). Moreover, GRP grafts into the contused spinal cord can reduce the expression of proteoglycans inhibitory for axonal regeneration (Hill et al., 2004). However, any regenerating axons would require remyelination by the engrafted GRPs. The possible contribution of regenerating fibers to the functional recovery observed in the present study remains to be determined. Although the early recovery of tcMMEP responses would be consistent with remyelination rather than regeneration, the significant locomotion recovery at weeks 5 and 6 after injury may also reflect regeneration.

These data support an emerging concept in designing strategies to repair the injured CNS; combination strategies will be necessary for optimal functional return (Lu et al., 2004; Pearse et al., 2004; Sivasankaran et al., 2004). Determining which combination of therapies to use is likely to be both lesion dependent and empirically delineated. Functionally useful remyelination by engrafted stem cells will require at least partial lineage restriction of the cells, appropriate trophic support, and inhibition of the signal cascades that preclude cell-specific differentiation.

\section{References}

Alexeeva N, Broton JG, Suys S, Calancie B (1997) Central cord syndrome of cervical spinal cord injury: widespread changes in muscle recruitment 
studied by voluntary contractions and transcranial magnetic stimulation. Exp Neurol 148:399-406.

Alexeeva N, Broton JG, Calancie B (1998) Latency of changes in spinal motoneuron excitability evoked by transcranial magnetic brain stimulation in spinal cord injured individuals. Electroencephalogr Clin Neurophysiol 109:297-303.

Bambakidis NC, Miller RH (2004) Transplantation of oligodendrocyte precursors and sonic hedgehog results in improved function and white matter sparing in the spinal cords of adult rats after contusion. Spine J 4:16-26.

Barres BA, Raff MC (1994) Control of oligodendrocyte number in the developing rat optic nerve. Neuron 12:935-942.

Barres BA, Raff MC, Gaese F, Bartke I, Dechant G, Barde YA (1994) A crucial role for neurotrophin-3 in oligodendrocyte development. Nature 367:371-375.

Basso DM, Beattie MS, Bresnahan JC (1995) A sensitive and reliable locomotor rating scale for open field testing in rats. J Neurotrauma 12:1-21.

Blight AR (1983) Cellular morphology of chronic spinal cord injury in the cat: analysis of myelinated axons by line-sampling. Neuroscience 10:521-543.

Blight AR (1993) Remyelination, revascularization, and recovery of function in experimental spinal cord injury. Adv Neurol 59:91-104.

Blight AR (2002) Miracles and molecules-progress in spinal cord repair. Nat Neurosci 5 [Suppl]:1051-1054.

Brustle O, Jones KN, Learish RD, Karram K, Choudhary K, Wiestler OD, Duncan ID, McKay RD (1999) Embryonic stem cell-derived glial precursors: a source of myelinating transplants. Science 285:754-756.

Bunge RP, Puckett WR, Becerra JL, Marcillo A, Quencer RM (1993) Observations on the pathology of human spinal cord injury. A review and classification of 22 new cases with details from a case of chronic cord compression with extensive focal demyelination. Adv Neurol 59:75-89.

Cao Q, Zhang YP, Iannotti C, DeVries WH, Xu XM, Shields CB, Whittemore SR (2005) Functional and electrophysiological changes after graded traumatic spinal cord injury in adult rat. Exp Neurol 191 [Suppl 1]:S3-S16.

Cao QL, Zhang YP, Howard RM, Walters WM, Tsoulfas P, Whittemore SR (2001) Pluripotent stem cells engrafted into the normal or lesioned adult rat spinal cord are restricted to a glial lineage. Exp Neurol 167:48-58.

Cao QL, Howard RM, Dennison JB, Whittemore SR (2002) Differentiation of engrafted neuronal-restricted precursor cells is inhibited in the traumatically injured spinal cord. Exp Neurol 177:349-359.

Chow SY, Moul J, Tobias CA, Himes BT, Liu Y, Obrocka M, Hodge L, Tessler A, Fischer I (2000) Characterization and intraspinal grafting of EGF/ bFGF-dependent neurospheres derived from embryonic rat spinal cord. Brain Res 874:87-106.

Coggeshall RE, Lekan HA (1996) Methods for determining numbers of cells and synapses: a case for more uniform standards of review. J Comp Neurol 364:6-15.

Cosgaya JM, Chan JR, Shooter EM (2002) The neurotrophin receptor p75NTR as a positive modulator of myelination. Science 298:1245-1248.

Crowe MJ, Bresnahan JC, Shuman SL, Masters JN, Beattie MS (1997) Apoptosis and delayed degeneration after spinal cord injury in rats and monkeys. Nat Med 3:73-76.

Engel U, Wolswijk G (1996) Oligodendrocyte-type-2 astrocyte (O-2A) progenitor cells derived from adult rat spinal cord: in vitro characteristics and response to PDGF, bFGF and NT-3. Glia 16:16-26.

Fehlings MG, Tator CH, Linden RD, Piper IR (1987) Motor evoked potentials recorded from normal and spinal cord-injured rats. Neurosurgery $20: 125-130$.

Franklin RJ, Hinks GL, Woodruff RH, O’Leary MT (2001) What roles do growth factors play in CNS remyelination? Prog Brain Res 132:185-193.

Gao M, Ping P, Post S, Insel PA, Tang R, Hammond HK (1998) Increased expression of adenylylcyclase type VI proportionately increases betaadrenergic receptor-stimulated production of cAMP in neonatal rat cardiac myocytes. Proc Natl Acad Sci USA 95:1038-1043.

Gensert JM, Goldman JE (1997) Endogenous progenitors remyelinate demyelinated axons in the adult CNS. Neuron 19:197-203.

Gledhill RF, Harrison BM, McDonald WI (1973) Demyelination and remyelination after acute spinal cord compression. Exp Neurol 38:472-487.

Guest JD, Hiester ED, Bunge RP (2005) Demyelination and Schwann cell responses adjacent to injury epicenter cavities following chronic human spinal cord injury. Exp Neurol 192:384-393.
Han SS, Liu Y, Tyler-Polsz C, Rao MS, Fischer I (2004) Transplantation of glial-restricted precursor cells into the adult spinal cord: survival, glialspecific differentiation, and preferential migration in white matter. Glia 45:1-16.

Hill CE, Proschel C, Noble M, Mayer-Proschel M, Gensel JC, Beattie MS, Bresnahan JC (2004) Acute transplantation of glial-restricted precursor cells into spinal cord contusion injuries: survival, differentiation, and effects on lesion environment and axonal regeneration. Exp Neurol 190:289-310.

Hofstetter CP, Holmstrom NA, Lilja JA, Schweinhardt P, Hao J, Spenger C, Wiesenfeld-Hallin Z, Kurpad SN, Frisen J, Olson L (2005) Allodynia limits the usefulness of intraspinal neural stem cell grafts; directed differentiation improves outcome. Nat Neurosci 8:346-353.

Horner PJ, Power AE, Kempermann G, Kuhn HG, Palmer TD, Winkler J, Thal LJ, Gage FH (2000) Proliferation and differentiation of progenitor cells throughout the intact adult rat spinal cord. J Neurosci 20:2218-2228.

Ishii K, Toda M, Nakai Y, Asou H, Watanabe M, Nakamura M, Yato Y, Fujimura Y, Kawakami Y, Toyama Y, Uyemura K (2001) Increase of oligodendrocyte progenitor cells after spinal cord injury. J Neurosci Res 65:500-507.

Jean I, Lavialle C, Barthelaix-Pouplard A, Fressinaud C (2003) Neurotrophin-3 specifically increases mature oligodendrocyte population and enhances remyelination after chemical demyelination of adult rat CNS. Brain Res 972:110-118.

Keirstead HS, Ben Hur T, Rogister B, O’Leary MT, Dubois-Dalcq M, Blakemore WF (1999) Polysialylated neural cell adhesion molecule-positive CNS precursors generate both oligodendrocytes and Schwann cells to remyelinate the CNS after transplantation. J Neurosci 19:7529-7536.

Keirstead HS, Nistor G, Bernal G, Totoiu M, Cloutier F, Sharp K, Steward O (2005) Human embryonic stem cell-derived oligodendrocyte progenitor cell transplants remyelinate and restore locomotion after spinal cord injury. J Neurosci 25:4694-4705.

Kinsella TM, Nolan GP (1996) Episomal vectors rapidly and stably produce high-titer recombinant retrovirus. Hum Gene Ther 7:1405-1413.

Kumar S, Kahn MA, Dinh L, De Vellis J (1998) NT-3-mediated TrkC receptor activation promotes proliferation and cell survival of rodent progenitor oligodendrocyte cells in vitro and in vivo. J Neurosci Res 54:754-765.

Liu S, Qu Y, Stewart TJ, Howard MJ, Chakrabortty S, Holekamp TF, McDonald JW (2000) Embryonic stem cells differentiate into oligodendrocytes and myelinate in culture and after spinal cord transplantation. Proc Natl Acad Sci USA 97:6126-6131.

Liu XZ, Xu XM, Hu R, Du C, Zhang SX, McDonald JW, Dong HX, Wu YJ, Fan GS, Jacquin MF, Hsu CY, Choi DW (1997) Neuronal and glial apoptosis after traumatic spinal cord injury. J Neurosci 17:5395-5406.

Loy DN, Magnuson DS, Zhang YP, Onifer SM, Mills MD, Cao QL, Darnall JB, Fajardo LC, Burke DA, Whittemore SR (2002) Functional redundancy of ventral spinal locomotor pathways. J Neurosci 22:315-323.

Lu P, Yang H, Jones LL, Filbin MT, Tuszynski MH (2004) Combinatorial therapy with neurotrophins and cAMP promotes axonal regeneration beyond sites of spinal cord injury. J Neurosci 24:6402-6409.

Magnuson DS, Trinder TC, Zhang YP, Burke D, Morassutti DJ, Shields CB (1999) Comparing deficits following excitotoxic and contusion injuries in the thoracic and lumbar spinal cord of the adult rat. Exp Neurol 156:191-204.

Mayer-Proschel M, Kalyani AJ, Mujtaba T, Rao MS (1997) Isolation of lineage-restricted neuronal precursors from multipotent neuroepithelial stem cells. Neuron 19:773-785.

McDonald JW, Liu XZ, Qu Y, Liu S, Mickey SK, Turetsky D, Gottlieb DI, Choi DW (1999) Transplanted embryonic stem cells survive, differentiate and promote recovery in injured rat spinal cord. Nat Med 5:1410-1412.

McTigue DM, Horner PJ, Stokes BT, Gage FH (1998) Neurotrophin-3 and brain-derived neurotrophic factor induce oligodendrocyte proliferation and myelination of regenerating axons in the contused adult rat spinal cord. J Neurosci 18:5354-5365.

McTigue DM, Wei P, Stokes BT (2001) Proliferation of NG2-positive cells and altered oligodendrocyte numbers in the contused rat spinal cord. J Neurosci 21:3392-3400.

Mujtaba T, Piper DR, Kalyani A, Groves AK, Lucero MT, Rao MS (1999) Lineage-restricted neural precursors can be isolated from both the mouse neural tube and cultured ES cells. Dev Biol 214:113-127.

Ogawa Y, Sawamoto K, Miyata T, Miyao S, Watanabe M, Nakamura M, Bregman BS, Koike M, Uchiyama Y, Toyama Y, Okano H (2002) Trans- 
plantation of in vitro-expanded fetal neural progenitor cells results in neurogenesis and functional recovery after spinal cord contusion injury in adult rats. J Neurosci Res 69:925-933.

Onifer SM, Magnuson DSK, Shield CB, Whittemore SR (2000) Grafting into the injured spinal cord to restore locomotion: two decades of promise yet to be fulfilled. Neurosci News 3:50-58.

Oorschot DE (1994) Are you using neuronal densities, synaptic densities or neurochemical densities as your definitive data? There is a better way to go. Prog Neurobiol 44:233-247.

Pearse DD, Pereira FC, Marcillo AE, Bates ML, Berrocal YA, Filbin MT, Bunge MB (2004) cAMP and Schwann cells promote axonal growth and functional recovery after spinal cord injury. Nat Med 10:610-616.

Plant GW, Currier PF, Cuervo EP, Bates ML, Pressman Y, Bunge MB, Wood PM (2002) Purified adult ensheathing glia fail to myelinate axons under culture conditions that enable Schwann cells to form myelin. J Neurosci 22:6083-6091.

Privat A (2003) Astrocytes as support for axonal regeneration in the central nervous system of mammals. Glia 43:91-93.

Rubio N, Rodriguez R, Arevalo MA (2004) In vitro myelination by oligodendrocyte precursor cells transfected with the neurotrophin-3 gene. Glia 47:78-87.

Scheff SW, Rabchevsky AG, Fugaccia I, Main JA, Lumpp Jr JE (2003) Experimental modeling of spinal cord injury: characterization of a forcedefined injury device. J Neurotrauma 20:179-193.

Schucht P, Raineteau O, Schwab ME, Fouad K (2002) Anatomical correlates of locomotor recovery following dorsal and ventral lesions of the rat spinal cord. Exp Neurol 176:143-153.

Shihabuddin LS, Horner PJ, Ray J, Gage FH (2000) Adult spinal cord stem cells generate neurons after transplantation in the adult dentate gyrus. J Neurosci 20:8727-8735.

Sim FJ, Zhao C, Penderis J, Franklin RJ (2002) The age-related decrease in CNS remyelination efficiency is attributable to an impairment of both oligodendrocyte progenitor recruitment and differentiation. J Neurosci 22:2451-2459.
Sivasankaran R, Pei J, Wang KC, Zhang YP, Shields CB, Xu XM, He Z (2004) $\mathrm{PKC}$ mediates inhibitory effects of myelin and chondroitin sulfate proteoglycans on axonal regeneration. Nat Neurosci 7:261-268.

Springer JE, Azbill RD, Knapp PE (1999) Activation of the caspase-3 apoptotic cascade in traumatic spinal cord injury. Nat Med 5:943-946.

Strohmaier C, Carter BD, Urfer R, Barde YA, Dechant G (1996) A splice variant of the neurotrophin receptor trkB with increased specificity for brain-derived neurotrophic factor. EMBO J 15:3332-3337.

Talbott JF, Loy DN, Liu Y, Qiu MS, Bunge MB, Rao MS, Whittemore SR (2005) Endogenous Nkx2.2(+)/Olig2(+) oligodendrocyte precursor cells fail to remyelinate the demyelinated adult rat spinal cord in the absence of astrocytes. Exp Neurol 192:11-24.

Totoiu MO, Keirstead HS (2005) Spinal cord injury is accompanied by chronic progressive demyelination. J Comp Neurol 486:373-383.

Tsoulfas P, Soppet D, Escandon E, Tessarollo L, Mendoza-Ramirez JL, Rosenthal A, Nikolics K, Parada LF (1993) The rat trkC locus encodes multiple neurogenic receptors that exhibit differential response to neurotrophin-3 in PC12 cells. Neuron 10:975-990.

Urfer R, Tsoulfas P, Soppet D, Escandon E, Parada LF, Presta LG (1994) The binding epitopes of neurotrophin-3 to its receptors trkC and gp75 and the design of a multifunctional human neurotrophin. EMBO J 13:5896-5909.

Waxman SG (1989) Demyelination in spinal cord injury. J Neurol Sci 91:1-14.

Xu XM, Guenard V, Kleitman N, Aebischer P, Bunge MB (1995) A combination of BDNF and NT-3 promotes supraspinal axonal regeneration into Schwann cell grafts in adult rat thoracic spinal cord. Exp Neurol 134:261-272.

Yamamoto S, Yamamoto N, Kitamura T, Nakamura K, Nakafuku M (2001) Proliferation of parenchymal neural progenitors in response to injury in the adult rat spinal cord. Exp Neurol 172:115-127.

Yan H, Wood PM (2000) NT-3 weakly stimulates proliferation of adult rat $\mathrm{O} 1(-) \mathrm{O} 4(+)$ oligodendrocyte-lineage cells and increases oligodendrocyte myelination in vitro. J Neurosci Res 62:329-335. 